put into the mixture, that is, the concentrations of base- $d$-acid and base- $l$-acid are equal to one another, as are those of $d$-acid and $l$-acid, and any subsequent changes are mutually compensating. The concentrations of the components are known only at this point and at that at which there is no excess of $d l$-acid present. Attractive as the problem is, there is as yet insufficient evidence for its complete solution.

Exchanges and inversions of these types must involve transition complexes such as

$$
d \text {-acid — base .....l-acid, }
$$

in which the base may be able to exert an asymmetric influence, on more than one molecule of acid. That this influence has to be more intimate than a purely environmental one would appear to be probable from some preliminary (unpublished) experimental results obtained by us in 1941, concerning the rates of mutarotation of the brucine salt of $l$-2-chloro-N-benzoyl- 6 methyldiphenylamine-2'-carboxylic acid, in solution in $d$-, $l$ - and $d l$-sec.-octyl alcohols. These rates, as measured, were experimentally indistinguishable, and although much more detailed work remains to be done, we are of the opinion that there has to be a fairly close association between the 'influence' and the labile substance for the latter to be affected. A similar conclusion follows from the many cases we have studied in which salt activation occurs in a nondissociating and not appreciably in a dissociating solvent.

The mechanism of "second order" asymmetric transformation has been understood for a considerable time (see, for example, Leuchs and Wutke ${ }^{8}$ ), but until the appearance of our recent memoir ${ }^{\theta}$ it had not been realized that if second order transformation, with separation of one pure diastereoisomeride, can occur in a non-dissociating solvent, then it must be preceded, that is, in solution, by a first order asymmetric transformation, optically antagonistic to the second order change, although the measurable effect of the first order change will in some cases be very small.

Bedford College,

M. M. JAMTSON.

University of London,

c/o University Chemical Laboratory, Cambridge.

March 16.

${ }^{1} J$. Chem. Soc., 127, 1572 (1925).

¿ J. Chem. Soc., 1291 (1928).

s J. Chem. Soc., 1646 (1938)

\J. Chem. Soc., 1650 (1938).

${ }^{5} J$. Chem. Soc., 266 (1940).

'J. Chem. Soc., 1650 (1938).

'J. Chem. Soc., 270,272 (1940).

- Ber., 46, 2420 (1913).

J. Chem. Soc., 437 (1942).

\section{Influence of Water Vapour upon the Combustion of Hydrocarbon Mixtures}

IT has been reported previously that flame gases resulting from the combustion of moist carbon monoxide - air and moist hydrogen - air mixtures attain higher temperatures than those resulting from the combustion of dry mixtures ${ }^{1.2}$. The temperatures were measured by means of very thin quartz-covered platinum-rhodium wires of overall diameter 0.0005 in. immersed in the flame gases just above the inner cone. The mixtures which were fed to the burner were on the weak side of the theoretical mixtures, and for any given combustible gas content the temperatures of the moist mixture flame gases were of the order of $50^{\circ} \mathrm{C}$. higher than those of the dry mixture flame gases.

Similar experiments have been carried out with moist and dry mixtures of air and butane, propane, ethane (which contained approximately 10 per cent of ethylene) and ethylene. The results of the experiments with ethane mixtures (which showed the largest differences) and with butane mixtures (which showed the smallest differences) are summarized in the accompanying graphs. It will be seen that in the case of the weakest mixtures used the moist ethane mixtures yielded temperatures some $70^{\circ} \mathrm{C}$. higher than the dry mixtures, whereas the moist butane mixtures yielded temperatures only about $25^{\circ} \mathrm{C}$. higher than the dry mixtures. It will also be seen that as the mixture strength was increased the differences between the moist and dry mixture temperatures became less and less, until mixture strengths were reached in which the proportion of the combustible gas was about 90 per cent of the theoretical proportion, when the moist and dry temperatures were sensibly the same. Similar results were obtained with the propane and ethylene mixtures.
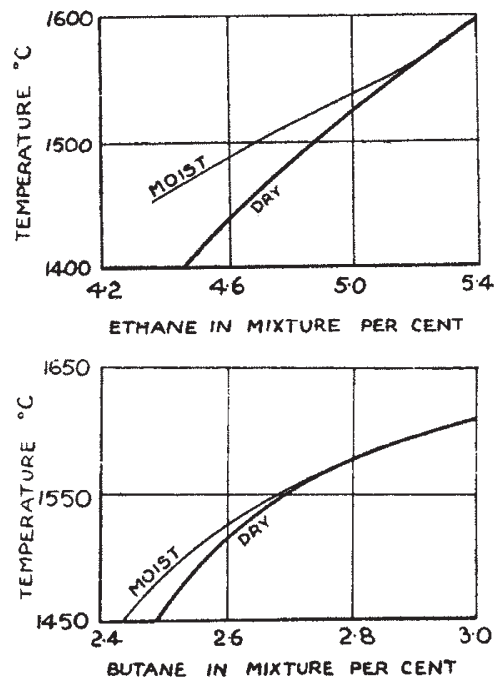

Reference to our previous letter relating to moist and dry hydrogen - air mixtures ${ }^{2}$ will show that in the case of the flame gases from these mixtures the differences in the quartz-covered wire temperatures also tended to become less as the mixture strength was increased. Thus, for mixtures containing 21 per cent hydrogen, the moist mixture temperature was about $50^{\circ} \mathrm{C}$. higher than the dry mixture temperature, but for mixtures containing 24 per cent hydrogen it was rather less than $40^{\circ} \mathrm{C}$. higher. Further experiment has shown that with still stronger mixtures the difference between the moist and dry mixture temperatures steadily decreases ; for mixtures containing 26 per cent hydrogen the difference was only about $20^{\circ} \mathrm{C}$.

It should perhaps be added that a burner of special design was employed in these experiments, and that the combustible gas - air mixtures fed to it were previously carefully mixed in a large tank.

$\begin{array}{cl}\text { Engineering Department, } & \text { W. T. David. } \\ \text { University, Leeds. } & \text { J. MaNN. }\end{array}$ March 10.

1 David and Pugh, Nators, 140, 1098 (1937).

2 David and Mann, Natore, 150, 521 (1942). 